\title{
Study on the Mechanism of Financial Support for the Urbanization in Guizhou Province
}

\author{
Chenggang Li, Xiaoliang Liu, Mingguo Zhang, Lingyun Luo and Yandan Xue \\ Faculty of Finance, Guizhou University of Finance and Economics, Guiyang, 550025, China
}

Keywords: Urbanization construction; Financial support; Multiple regression model

\begin{abstract}
Studying on the mechanism of financial support for the urbanization of Guizhou Province is conducive to improve the urbanization level in Guizhou Province. This paper uses multivariate regression model, empirically analyze of the mechanism of the financial support for the urbanization in Guizhou Province. The empirical results shows the total amount of deposits and loans, fixed assets investment and public expenditure have a positive impact on the urbanization construction in Guizhou Province. Among them, the impact of the total amount of deposits and loans and fixed assets investment on the urbanization construction of Guizhou Province is significant. However, the impact of public expenditure on the urbanization construction in Guizhou Province is not significant.
\end{abstract}

\section{Introduction}

Because the urbanization construction needs a lot of capital, so the urbanization construction can not be separated from the financial support. Finance in the tertiary industry is in a leading position. Through the intermediary role of the funds transfer and the allocation of resources, finance allocates the capital accumulation and dispersion to capital surplus, and have a positive impact on the real economy, so as to promote the development of urbanization. Research on the mechanism of financial support for the urbanization of Guizhou Province is conducive to the urbanization development in Guizhou Province, and improve urbanization level in Guizhou Province.

\section{Literature Review}

Many scholars' researches have indicated that finance has played a huge role in the development of urbanization. Jiang and Chen (2003) pointed out that urbanization may pose a threat to the ecological environment, and must do a good job in the protection of the ecological environment, in order to truly realize the significance of the development of urbanization.

Using the non-structural vector autoregressive (VAR) model, through the data analysis, Huang and Xie (2008) concluded that there is a causal relationship between bank loan and urbanization construction .Bank loan is helpful to the urbanization construction, but branches of the financial system is becoming more and more desalination demand for urban construction funds. There are some policy suggestions as follows: to enrich and improve the urban financial system service system, perfect fuse processing system and strictly deal with the relationship between government and branches of financial institutions, strengthen the financial support.

Chen (2013) clearly pointed out that, we should adhere to Chinese characteristics of the new industrialization, informatization, urbanization, agricultural modernization. How to improve the efficiency of the financial system, so as to fully protect the liquidity in the urbanization construction, has become the main direction and goal of China's economic development in the future. Mathur (2013) studied the self-financing urbanization of Gujarat state, India, and thought that rapid land appreciation of developed cities, local governments and rotary funds system are three key factors of self-financing urbanization. Zhou (2013) analyzed the relationship between urbanization and financial support in the Southwest ethnic regions. The analysis found that the financial support of Southwest Minority Areas is weak. 


\section{Analysis of the Mechanism of Financial Support for Urbanization in Guizhou Province}

The efficient operation of the financial system to speed up the process of urbanization, and achieve economic stability and healthy development have important significance. According to the theory of financial development, finance can be in an uncertain environment to achieve the optimal allocation of resources, which is one of its most important function. The mechanism of financial support for the urbanization construction is realized through the following aspects:

Firstly, urbanization needs long-term liquidity injections. Under the control of liquidity risk, investors are always less choice medium or long term projects. Financial liquidity creation provides a convenient for investors realized investment projects, has a underestimated power to extend the capital cycle and optimize the allocation of capital so as to promote the process of urbanization.

Secondly, as a financial intermediary system for the exchange of information between the financial system, communication has played a role in the media. Through high-tech information technology, especially the Internet and mobile communications, finance is efficient to achieve the information exchange in the financial market and save the middle cost. Finance use the full range of market related information, to pick out some industries and enterprises which adapt to the current urbanization policy background, and achieve the real advantage that are low risk and high return. Thus, finance can give capital resources priority to these industries and enterprises, so as to greatly promoted the development of urbanization.

Thirdly, mobilize savings to provide financing for urbanization. Finance ensures that the city economic system in the normal conduct of savings and investments. The development of the entire financial system, not only can reduce the economic cost of urbanization development, improve the process of urbanization in the capital reserves, but also for inject liquidity to the development of urbanization.

\section{Empirical Analysis on the Role of Financial Support for the Urbanization of Guizhou Province}

Variable Selection. Dependent Variable. This paper studies the mechanism of financial support for the development of urbanization in Guizhou Province, analyzing the supporting role of financial development in the development of urbanization in Guizhou Province. Therefore, the dependent variable of this paper is the level of urbanization development in Guizhou Province. The development level of urbanization in Guizhou Province is calculated by the following formula:

$$
U R B=\frac{\text { Urban } \text { populaiton }}{\text { Total populaiton }}
$$

Independent Variables. There are many variables to measure the financial development, such as financial institutions, deposit and loan size, industry investment funds and insurance funds, and so on. Due to the financial development of Guizhou Province is lagging, a lot of data to measure financial development can not be founded. Therefore, this paper choose deposit and loan balances, fixed asset investment and public expenditure to measure the financial development of Guizhou Province.

Data Sources and Processing. The data of this paper comes from the website of Guizhou Provincial Bureau of Statistics (http://www.gz.stats.gov.cn/Web 62/). The time interval in this paper is between 2000 and 2014. The empirical data in this paper are shown in the following table. In order to reduce the variance, the data of each variable is processed by logarithm.

Model Construction. This paper uses multiple regression model to empirically analyze the financial support for the urbanization in Guizhou Province. The model is constructed as follows:

$$
U R B_{t}=\alpha+\beta_{1} C D K_{t}+\beta_{2} I N V_{t}+\beta_{3} F I E_{t}+\mu
$$

Among them, $U R B$ represents the urbanization level of Guizhou Province, $C D K$ represents deposit and loan balance, INV represents the amount of investment in fixed assets, FIE 
represents the public finance expenditure. $\alpha$ represents constant. $\beta_{1}, \beta_{2}, \beta_{3}$ respectively represents the coefficient of each variable. $\mu$ represents the error term of the model.

Table 1 Empirical data

\begin{tabular}{|c|c|c|c|c|}
\hline Year & Urbanization & $\begin{array}{l}\text { Deposit and loan } \\
\text { balance }(100 \text { million } \\
\text { yuan) }\end{array}$ & \begin{tabular}{|lr|} 
& \multicolumn{2}{l}{ Investment in fixed } \\
assets $\quad(100 \quad$ million \\
yuan)
\end{tabular} & $\begin{array}{l}\text { Fiscal expenditure (100 } \\
\text { million yuan) }\end{array}$ \\
\hline 2000 & $23.87 \%$ & 2171.46 & 402.5 & 201.57 \\
\hline 2001 & $23.96 \%$ & 2553.34 & 533.74 & 275.2 \\
\hline 2002 & $24.29 \%$ & 2956.92 & 632.44 & 316.67 \\
\hline 2003 & $24.77 \%$ & 3612.66 & 754.13 & 332.35 \\
\hline 2004 & $26.28 \%$ & 4342.31 & 869.25 & 418.42 \\
\hline 2005 & $26.87 \%$ & 5081.47 & 1018.25 & 520.73 \\
\hline 2006 & $27.46 \%$ & 5996.19 & 1197.68 & 610.64 \\
\hline 2007 & $28.24 \%$ & 6955 & 1488.8 & 795.4 \\
\hline 2008 & $29.11 \%$ & 8306.2 & 1864.45 & 1055.39 \\
\hline 2009 & $29.89 \%$ & 10554.76 & 2450.99 & 1372.27 \\
\hline 2010 & $33.81 \%$ & 13111.45 & 3186.28 & 1631.48 \\
\hline 2011 & $34.96 \%$ & 15584.71 & 5101.55 & 2249.4 \\
\hline 2012 & $36.41 \%$ & 18814.84 & 5717.8 & 2755.68 \\
\hline 2013 & $37.83 \%$ & 23369.31 & 7373.6 & 3082.66 \\
\hline 2014 & $40.01 \%$ & 27631.56 & 9025.75 & 3542.8 \\
\hline
\end{tabular}

Unit Root Test. It maybe appear the "pseudo regression" phenomenon in modeling the time series data. In order to avoid the "pseudo regression" phenomenon, we need to do unit root test. In this paper, the ADF test is used to test the unit root of each variable. Unit root test results are shown in Table 2. It is can be seen from Table 2 that the original sequence of each variable is not a non-stationary time series. The first order difference is a stationary time series.

Table 2 Unit root test results

\begin{tabular}{|l|l|l|l|}
\hline Variable & t-Statistic & Prob & Conclusion \\
\hline LNURB & 1.978445 & 0.9994 & Nonstationary \\
\hline LNCDK & 1.415273 & 0.9977 & Nonstationary \\
\hline LNINV & 0.752282 & 0.9886 & Nonstationary \\
\hline LNFIE & -0.313609 & 0.8999 & Nonstationary \\
\hline DLNURB & -3.510419 & 0.0257 & Stationary \\
\hline DLNCDK & -3.176517 & 0.0475 & Stationary \\
\hline DLNINV & -3.599369 & 0.0221 & Stationary \\
\hline DLNFIE & -3.216048 & 0.0425 & Stationary \\
\hline
\end{tabular}

Empirical Results Analysis. The parameters of the model (2) were estimated using the Eviews8.0 model, and the results are shown in Table 3.

It can be seen from Table 3, Adjusted R-squared value is 0.9805. F-statistic value is 235.1546, and its adjoint probability is 0.0000 . This shows that the fitting effect of the model is good. The Durbin-Watson stat value is 1.9467 , which is in the vicinity of 2 . This shows that there is no multiple co-linearity between the variables. 
Table 3 Regression results

\begin{tabular}{|l|l|l|l|l|}
\hline Variable & Coefficient & Std. Error & t-Statistic & Prob. \\
\hline C & -2.7456 & 0.3334 & -8.2362 & 0.0000 \\
\hline LNCDK & 0.0662 & 0.1103 & 0.6002 & 0.5605 \\
\hline LNINV & 0.2216 & 0.0803 & 2.7615 & 0.0185 \\
\hline LNFIE & 0.1072 & 0.0882 & 1.2149 & 0.0498 \\
\hline R-squared & 0.9846 & Mean dependent var & -1.2237 & \\
\hline Adjusted R-squared & 0.9805 & S.D. dependent var & 0.1757 & \\
\hline S.E. of regression & 0.0246 & Akaike info criterion & -4.3521 & \\
\hline Sum squared resid & 0.0066 & Schwarz criterion & -4.1633 & \\
\hline Log likelihood & 36.6410 & Hannan-Quinn criter. & -4.3541 & \\
\hline F-statistic & 235.1546 & Durbin-Watson stat & 1.9467 & \\
\hline Prob(F-statistic) & 0.0000 & \multicolumn{3}{|l|}{} \\
\hline
\end{tabular}

According to the coefficients of each variable, the coefficient of the deposit and loan balance is 0.0662 and it is positive. Its adjoint probability is 0.5605 . This shows that deposit loan balance has a positive impact on the urbanization in Guizhou Province, but the impact was not significant. The coefficient of fixed asset investment is 0.2216 . It is a positive number. This indicates that the investment in fixed assets has a positive impact on the urbanization in Guizhou Province, and the impact was significant. The coefficient of public expenditure is 0.1072 , and its adjoint probability is 0.0498. This shows that the public finance expenditure has a significantly positive impact on the urbanization of Guizhou Province.Therefore, the financial development provide a support for the urbanization in Guizhou Province.

\section{Conclusion}

This paper first analyzes the mechanism of the financial support for the urbanization in Guizhou Province, and then uses the multiple regression model to empirically analyze the financial support for the urbanization in Guizhou Province. The empirical results show that the deposits and loans balance, fixed assets investment and public expenditure positively impact on the urbanization construction in Guizhou Province. Among them, the fixed assets investment and public expenditure are significantly positively impact on urbanization construction in Guizhou Province. But the impact of deposits and loans balance on the urbanization construction in Guizhou Province is not significant.

\section{References}

[1] M. Jiang, J. Chen. The sustainable development of urbanization and city [J]. Journal of Northeast Forestry University, 2003, 31(2): 52-53.

[2] Y. Huang, Z. Xie. Analysis on the effect of financial support in the construction of urbanization [J]. Theory Exploration, 2008, (3): 91-93.

[3] Y. Chen. Financial support for the construction of new urbanization in China [J]. Economic Research, 2013, (2):10-12.

[4] S. Mathur. Self-financing urbanization: Insights from the use of Town Planning Schemes in Ahmadabad, India [J]. Cities, 2013, 31: 308-316. 
[5] Y. Zhou. Urbanization and Financial Support in Southwest Ethnic Minority Area [J]. Guizhou Ethnic Studies, 2013, (5): 132-135. 